\title{
Classification and Application of Roof Stability of Bolt Supporting Coal Roadway Based on BP Neural Network
}

\author{
Heng Ren, ${ }^{1}$ Yongjian Zhu $\mathbb{D}^{1,},{ }^{1,2}$ Ping Wang, ${ }^{1,2,3}$ Peng Li, ${ }^{1}$ Yuqun Zhang, ${ }^{1}$ Xizhi Wang, \\ and Yingying $\mathbf{L i}^{1}$ \\ ${ }^{1}$ School of Resource \& Environment and Safety Engineering, Hunan University of Science and Technology, \\ Xiangtan 411201, China \\ ${ }^{2}$ Work Safety Key Lab on Prevention and Control of Gas and Roof Disasters for Southern Goal Mines, \\ Hunan University of Science and Technology, Xiangtan 411201, Hunan, China \\ ${ }^{3}$ Hunan Provincial Key Laboratory of Safe Mining Techniques of Coal Mines, Hunan University of Science and Technology, \\ Xiangtan 411201, Hunan, China
}

Correspondence should be addressed to Yongjian Zhu; yjzhu@hnust.edu.cn

Received 19 July 2020; Revised 16 September 2020; Accepted 20 October 2020; Published 17 November 2020

Academic Editor: Fengqiang Gong

Copyright (c) 2020 Heng Ren et al. This is an open access article distributed under the Creative Commons Attribution License, which permits unrestricted use, distribution, and reproduction in any medium, provided the original work is properly cited.

In view of the frequent occurrence of roof accidents in coal roadways supported by bolts, the widespread application of bolt support technology in coal roadways has been restricted. Through on-site investigation, numerical analysis, and other research methods, 6 evaluation indicators were determined, and according to the relevant evaluation factors and four types of coal roadway roof stability, a neural network structure for roof stability prediction was constructed to realize the quantitative prediction of the roof stability of bolt-supported coal roadway. The method of adding momentum is used to improve the BP neural network algorithm. After passing the simulation test, it is applied to the field experiment of the roof stability classification. In order to facilitate on-site application, on the basis of the established BP neural network prediction model, a coal mine roof stability classification software recognition system was developed. Using the developed software system, the stability of coal roadway roof is classified into mine, coal seam, and region. According to the recognition result, the surfer software is used to draw the contour map of the stability of the roof of each coal mining roadway. The classification results are consistent with the actual situation on site.

\section{Introduction}

China has applied anchor rods to coal mine tunnels since 1956. After several technical breakthroughs, bolt support has become the main support structure of coal mine tunnels at present [1-3]. As a world-class large-scale modern mining area, Shendong Mining Area has more than 95\% of coal lanes supported by bolts. Compared with traditional support methods, bolt support technology has significant technical and economic advantages in controlling the surrounding rock deformation of coal roadway. However, there are also two outstanding problems in the bolt support of the production mines in the mining area. On the one hand, the bolt support design is too conservative; on the other hand, the roof accidents of the bolt support coal roadway also occur frequently [4-6], which becomes the restrictive factor for the widespread application of the bolt support technology in the coal roadway. According to the statistics of coal mine accidents in the country from 2007 to 2016, the number of roof accidents accounts for about $50 \%$ of the total coal mine accidents, and the death toll of roof accidents accounts for $35.5 \%$ [7]. Table 1 shows the statistics of four typical roof accidents in coal mines in China from 2017 to 2019. The supporting forms are all bolt and cable combined supporting forms [8]. As coal mining develops deeper, the geological structure is more complex and the impact of mining is more severe. Security issues have become the focus of attention. Therefore, the classification of roof stability of coal roadway 
TABle 1: Part of roof accident in coal mine in China from 2017 to 2019.

\begin{tabular}{lcclc}
\hline Coal mine name & Province & Support form & Cause of accident & Death toll \\
\hline Lijiagou coal mine & Shanxi & Anchor cable combination & Roof fall accident \\
Longyun coal mine & Shandong & Anchor cable combination & Roof fall accident \\
Hongyang coal mine & Liaoning & Anchor cable combination & Roof fall accident \\
Danshuigou coal mine & Shanxi & Anchor cable combination & Roof fall accident \\
\hline
\end{tabular}

with bolt support in Shendong mining area is a practical need for high production, high efficiency, and safe production in mining area [9].

At present, many new methods have been applied to the practice of surrounding rock classification in underground engineering and have made great progress, such as risk matrix methods [10], fuzzy mathematics and euthenics [11], and extension theory [12]. However, there is a complex nonlinear relationship between the stability of surrounding rock in underground engineering and its influence factors. Moreover, these influencing factors themselves have a high degree of ambiguity, randomness, and uncertainty, which limits their application to the evaluation of the stability of complex surrounding rocks. In recent years, neural networks have achieved significant results [13, 14]. Especially, BP neural networks have been widely used in the fields of pattern recognition, classification, nonlinear dynamic processing, automatic control, and prediction [15-18]. For nonlinear relationships, BP neural network has a high modeling ability. To this end, the paper uses BP neural network to classify the roof stability of coal roadway supported by bolts in Shendong mining area.

\section{Classification of Roof Stability}

The reasonable division of roof stability types directly relates to the question of whether the classification results are accurate and reliable, whether they are in line with the actual conditions of on-site engineering, and whether they can be applied on site. In paper, the roof stability classification is based on the geological conditions, engineering conditions, and on-site bolt support engineering practice of the bolt support coal roadway in Shendong mining area, and the roof support roof of coal mine is divided into several different types of stability. Stable type (I): simple support or single bolt support; medium stable type (II): ordinary anchor net support, falling type (III): anchor net + beam + cable support, and easy falling type (IV): anchor net beam cable support + wood pile and other combined support. The stable classification of the roof of coal roadway supported by bolts is shown in Figure 1.

\section{Stability Classification Index of Bolt Support Coal Roadway in Shendong Mining Area}

The scientific roof stability classification method should comprehensively consider the factors that affect the roof stability and select the most important influencing factors. Participate in the classification of surrounding rock stability as a classification index. Whether the classification index is accurate and comprehensive will directly affect the accuracy and reliability of the classification results. A comprehensive and in-depth analysis of the factors influencing the roof stability of coal roadway supported by bolts in Shendong mining area is carried out, and the main factors affecting the roof stability in Shendong mining area are obtained [9]. The main factors include top rock layer structure, mining influence, rock mass strength, roadway span, and roadway burial depth. However, how to choose the appropriate classification index among these influencing factors is still the key to whether the classification result is reliable and practical.

(1) Roof rock structure: there is currently no suitable single quantitative indicator for roof rock structure. Within a certain range of roadway direct roofing, whether there is a thick stable rock layer at the surface of the roof, how stable the thick stable rock layer is, and how far the thick stable rock layer is from the roof surface are the determinants of the influence of the roof rock structure on the roof stability. And according to the engineering characteristics of bolt support, the existence of this thick stable rock layer, its own stability, and its distance from the roadway roof surface are the keys to determine the bolt support parameters and support form. Therefore, for roof rock structure, the following indicators can be taken to participate in the classification of roof stability.

(1) The thickness of the single-layer rock layer closest to the roof surface is denoted by $D$ and the unit is $m$.

(2) The distance between the single-layer thick rock layer and the roof surface is denoted by $L$ and the unit is $m$.

(3) Strength includes three aspects of tensile strength, compressive strength, and shear strength. Theoretical studies have shown that the compressive strength of a single rock layer has the greatest impact on roof stability. Therefore, in paper, the uniaxial compressive strength of a single thick rock layer is expressed by $\sigma \mathrm{c}$, and the unit is $\mathrm{MPa}$.

(4) The span is the actual span of the roadway, which is denoted by B and the unit is $m$.

(2) Impact of mining; mining influence refers to the factors that affect the stability of the roof of the mining roadway within a certain range from the working face during the progress of the mining face. Literature [13] research shows that when the mining face advances, the roof pressure of the mining 


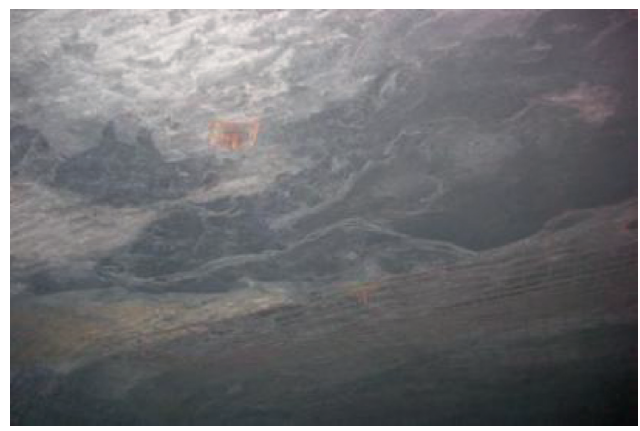

(a)

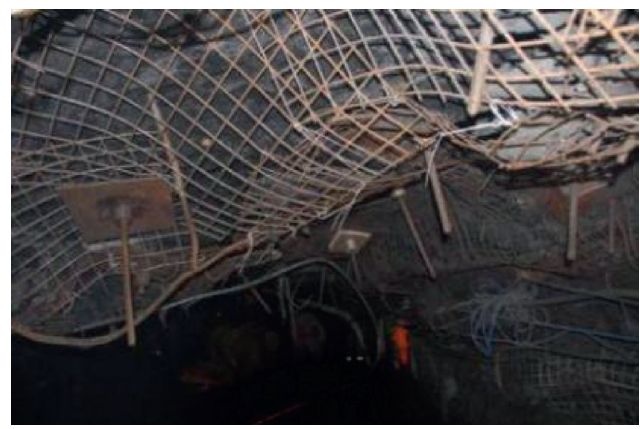

(c)

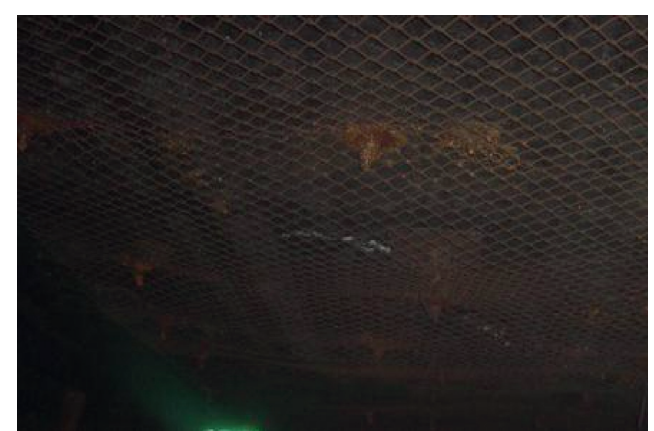

(b)

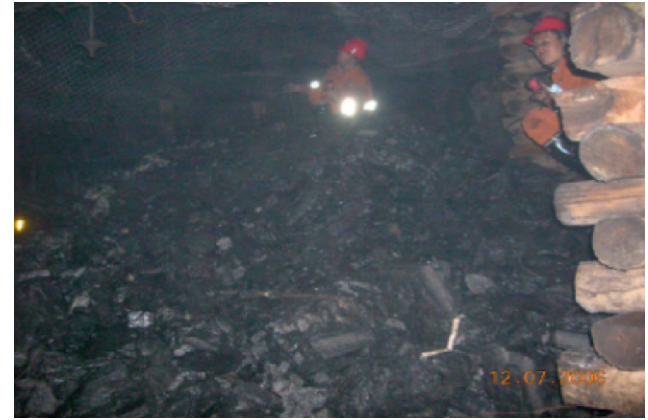

(d)

Figure 1: Site map of different stable types of coal roadway roof. (a) Stable. (b) Medium stable. (c) Falling. (d) Easy to fall.

roadway is within a certain range from the working face, and the degree of the roof thickness is related to the roadway direct roof thickness. The apparent degree of lateral pressure has a significant relationship with the mining height of the working face. That is to say, when the mining face advances, the mining pressure caused in the mining roadway is related to the ratio of the roadway direct roof thickness to the mining height (indicated by $N$, without units). Therefore, the ratio of the direct roof thickness of the roadway to the mining height can be used to replace the degree to which the mining roadway is affected by mining during mining.

(3) The roadway is buried deep. Roadway burial depth is the actual burial depth of coal roadway, and the unit is $m$.

Accordingly, the classification indicators in paper are six classification indicators, including the thickness $D$ (unit: $m$ ) of the single-layer thick rock layer closest to the roof surface, the uniaxial compressive strength $\sigma_{c}$ (unit: $M P a$ ) of the single-layer thick rock layer, the distance $L$ (unit: $m$ ) from the single-layer thick rock layer to the roof surface, the ratio of the index reflecting the influence of mining to the direct roof thickness and the mining height, $N$ (no unit), the roadway span $B$ (unit: $m$ ), and the roadway depth $H$ (unit: $m$ ).

3.1. Determination of Evaluation Factors. After determining the classification index value method and the type of roof stability of coal roadway supported by bolts in the mining area, it is necessary to determine a reasonable evaluation factor for various stable roof types before the classification model is established. The so-called evaluation factor is the corresponding value range of the six classification indicators of each stable type roof. Determining whether the basis of the evaluation factor is sufficient is the key to determine whether the classification model can effectively identify and whether the classification results are reliable. The basis for determining the evaluation factors of each stability type in this paper is based on the previous theoretical research results [9], combined with the actual maintenance status of coal roadway roof in Shendong mining area and the case analysis results of a large number of bolts supporting coal roadway roof fall in the mining area. Therefore, the evaluation factors of all classification indexes and their corresponding roof stability types are determined. The results are shown in Table 2 (original data) and Table 3 (standardized data).

\section{Design and Inspection of BP Neural Network Structure}

4.1. Improvement of BP Neural Network Algorithm. Due to the nonlinear nature of the neural network, the learning process is an analytical unconstrained nonlinear optimization process. And the BP algorithm uses the steepest descent method in the basic calculation principle. Such a method has some defects. One is how to set the value of $\eta$. If it is too large, it will cause oscillation. If it is too small, it will form a local minimum and not get the overall optimal, which will reduce the convergence speed and increase the amount of calculation. The second is that some calculation steps will reduce the error for some samples, while some samples are 
TABLE 2: The roof stability type and the original data of each index evaluating gene.

\begin{tabular}{|c|c|c|c|c|c|c|}
\hline Evaluation factor & $\begin{array}{c}L \\
(\mathrm{~m})\end{array}$ & $\begin{array}{c}D \\
(\mathrm{~m})\end{array}$ & $\begin{array}{c}\sigma_{c} \\
(\mathrm{MPa})\end{array}$ & $\begin{array}{c}B \\
(\mathrm{~m})\end{array}$ & $\begin{array}{c}N \\
/\end{array}$ & $\begin{array}{c}H \\
(\mathrm{~m})\end{array}$ \\
\hline Stable (class I) & 0 & $>1.56$ & $60 \sim 80$ & $<4.5$ & $0 \sim 1$ & $<100$ \\
\hline Medium stable type (class II) & $0 \sim 3.0$ & $1.56 \sim 1.20$ & $40 \sim 60$ & $4.5 \sim 5.2$ & $1 \sim 2$ & $100 \sim 160$ \\
\hline Falling type (class III) & $3.0 \sim 6.5$ & $1.20 \sim 0.67$ & $30 \sim 40$ & $5.2 \sim 6.0$ & $2 \sim 3$ & $160 \sim 300$ \\
\hline Easy to fall type (class IV) & $>6.5$ & $<0.67$ & $<30$ & $7.5 \sim 8.5$ & $3 \sim 4$ & $>300$ \\
\hline
\end{tabular}

TABLE 3: The roof stability type and the standardized data of each index evaluating gene.

\begin{tabular}{|c|c|c|c|c|c|c|}
\hline Evaluation factor & $L$ & $D$ & $\sigma_{\mathrm{c}}$ & $B$ & $N$ & $H$ \\
\hline Stable (class I) & 0 & $>1.00$ & $0.75 \sim 1.00$ & $<0.53$ & $0 \sim 0.25$ & $<0.33$ \\
\hline Medium stable type (class II) & $0 \sim 0.46$ & $1.00 \sim 0.77$ & $0.50 \sim 0.75$ & $0.53 \sim 0.61$ & $0.25 \sim 0.50$ & $0.33 \sim 0.53$ \\
\hline Falling type (class III) & $0.46 \sim 1.00$ & $0.77 \sim 0.43$ & $0.38 \sim 0.50$ & $0.61 \sim 0.71$ & $0.50 \sim 0.75$ & $0.53 \sim 1.00$ \\
\hline Easy to fall type (class IV) & $>1.00$ & $<0.43$ & $<0.38$ & $0.88 \sim 1.00$ & $0.75 \sim 1.00$ & $>1.00$ \\
\hline
\end{tabular}

not, so the number of iterations increases significantly and the convergence speed is slow. As can be seen from many improved algorithms, adding a momentum term to the BP algorithm can not only fine-tune the correction amount of the weight but also prevent learning from falling into a local minimum. Therefore, this article adopts the method of adding momentum terms when improving the BP algorithm, even if

$$
\Delta w_{i j}(n)=\alpha \Delta w_{i j}(n-1)+\eta \delta_{j}(n) v_{i}(n) .
$$

Rewrite the above formula as a time series with $t$ as the variable, $t$ from 0 to $n$; then, the above formula can be regarded as the first-order difference equation of $\Delta w_{i j}(n)$ :

$$
\Delta w_{i j}(n)=\eta \sum_{t=0}^{n} \alpha^{n-1} \delta_{j}(t) v_{i}(t) .
$$

Due to

$$
\begin{aligned}
v_{j}(n) & =f\left(u_{j}(n)\right), \\
\delta_{j}(n) v_{i}(n) & =-\frac{\partial E(n)}{\partial w_{i j}(n)} .
\end{aligned}
$$

So,

$$
\Delta w_{i j}(n)=-\eta \sum_{t=0}^{n} \alpha^{n-1} \frac{\partial E(t)}{\partial w_{i j}(t)} .
$$

In equation 4 , the correction amount $\Delta w_{i j}(n)$ is the sum of a series of weighted exponential sequences. When the momentum constant satisfies $0<|\alpha|<1$, the sequence converges. When $\alpha=0$, the above formula does not contain the momentum term. In theory, $\alpha$ can be either positive or negative. However, in practical applications, $\alpha$ cannot take negative numbers. When the current $\partial E(n) / \partial w_{i j}$ is the same as the previous symbol, the weighted summation value increases, making $\Delta w_{i j}(n)$ larger, thus accelerating the adjustment speed during stable adjustment. When $\partial E(n) / \partial w_{i j}$ is opposite to the previous sign, the result of exponentially weighted summation reduces $\Delta w_{i j}(n)$ and plays a stabilizing role.
4.2. Design of BP Model for Roof Stability Classification. There are 6 indicators selected in this paper to participate in the classification of roof stability. Therefore, the input layer of the neural network model is designed as 6 neurons, that is, the input layer contains 6 nodes. There are four different types of classification results in this article. Therefore, the output layer is designed as 4 neurons, and the output codes represent different stable types of top plates. The expected output of the four nodes in this article and the codes of the various stable type roofs are 1.000 .000 .000 .00 (class I stable type); 0.001 .000 .000 .00 (class II medium stable type); 0.000 .001 .000 .00 (class III falling type); and 0.000 .000 .001 .00 (category IV easy to fall type).

Because this article uses a three-layer BP neural network, the number of neurons in the middle hidden layer has no theoretical value. Different researchers will determine the number of neurons in the hidden layer according to the needs of the problem being solved. However, the determination of the number of neurons in the middle hidden layer must meet two basic principles:

(1) Ensure that the network can converge to the required accuracy

(2) Can effectively improve the convergence speed of the network.

In this paper, the reliability and accuracy of the classification results of roof stability of bolt-supported coal roadway in Shendong mining area should be guaranteed. With the input layer and output layer unchanged, five network topologies of 6 : $9: 4,6: 11: 4,6: 14: 4,6: 17: 4$, and $6: 20: 4$ were constructed, respectively, learning training for the same group of learning samples. Under the condition of the same number of iterations, the optimal network topology is determined according to the size of the simulation error after learning.

The training error of the comprehensive sample can be regarded as the optimal topology of $6: 20: 4$. The absolute errors are $0.0002,0.0004,0.0001,0.0007,0.0001,0.0003$, $0.0009,0.0018,0.0022,0.0001,0.0003$, and 0.0007 . The absolute value of the error is 0.0022 at the maximum and 0.0001 at the minimum, which meets the system's requirements for error accuracy. Therefore, the network 


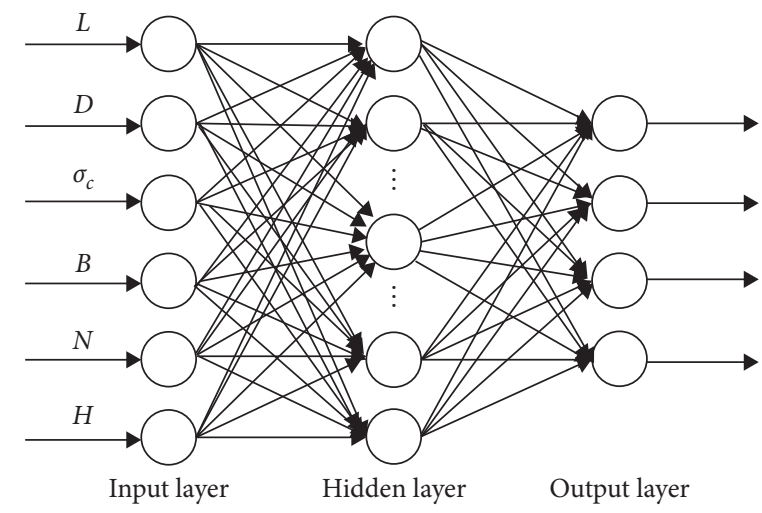

FIgURE 2: Structure design Figure of BP artificial neural network.

TABLE 4: Testing samples.

\begin{tabular}{lcccccccr}
\hline \multirow{2}{*}{ Sample number } & \multicolumn{4}{c}{ Test sample } & \multicolumn{2}{c}{ Type of roof stability } & Stable type code \\
\hline 1 & $L$ & $D$ & $\sigma_{c}$ & $B$ & $N$ & $H$ & IV & 0.000 .000 .001 .00 \\
2 & 3.00 & 0.24 & 0.29 & 0.92 & 0.81 & 1.04 & III & 0.000 .001 .000 .00 \\
3 & 0.49 & 0.59 & 0.42 & 0.62 & 0.65 & 0.63 & I & 1.000 .000 .000 .00 \\
4 & 0 & 1.49 & 0.76 & 0.52 & 0 & 0.34 & III & 0.000 .001 .000 .00 \\
5 & 0.80 & 0.47 & 0.45 & 0.70 & 0.60 & 0.66 & II & 0.001 .000 .000 .00 \\
6 & 0.35 & 0.98 & 0.68 & 0.60 & 0.41 & 0.46 & IV & 0.000 .000 .001 .00 \\
7 & 2.20 & 0.12 & 0.22 & 0.90 & 0.87 & 1.33 & I & 1.000 .000 .000 .00 \\
8 & 0 & 1.38 & 0.84 & 0.50 & 0 & 0.17 & II & 0.001 .000 .000 .00 \\
\hline
\end{tabular}

topology to be adopted in this paper is $6: 20: 4$, that is, the input layer has 6 neurons, the middle layer has one layer, the number of neurons is 20, and the output layer has 4 neurons, which are the top plate stability type codes. The established three-layer BP neural network model is shown in Figure 2.

4.3. Test of BP Neural Network Model. Using the BP neural network model after learning and training, 8 sets of test samples of four roof stability types corresponding to four different support methods in the mining area were selected (as shown in Table 4). According to the borehole analysis of the location of the tunnel and the actual engineering status of the tunnel, the model is tested to determine its reliability.

The above network calculation and output results show that the network has very good learning performance, the actual output of the network and the target output have achieved good agreement, and the network recognition accuracy rate is $100 \%$ (as shown in Table 5). Based on this, a BP neural network prediction model for coal roadway stability classification in Shendong mining area was established. In order to make the established BP neural network prediction model better applied in the field, Matlab6.5 programming is still used to develop a classification and recognition system for the roof stability of bolt-supported coal roadways in Shendong mining area. Its operation interface is shown in Figure 3.

The specific operation steps of the stability classification and identification system for the roof of coal roadway supported by bolts in Shendong mining area are as follows:
(1) Use Matlab6.5 software to call the prepared system software interface program, run the program, and the program ends. The system will display the interface of the stability classification and identification system for the roof of coal roadway supported by bolts in Shendong Mine, as shown in Figure 3.

(2) Press the sample training button, the system will automatically call the input training sample and run the training program of the neural network. When the set system error accuracy of 10-5 is reached, the training automatically stops. At this time, the identification system can be used to identify and classify the stability of the roof.

(3) Enter the six input parameters for the stability classification of the roof, respectively. Press Start to identify the button, and the display result window of the interface will automatically display the type of the top panel stability.

\section{Field Application}

Based on the developed classification software recognition system for roof stability of coal roadway with bolt support in Shendong mining area, Baode Coal Mine 8\# coal, Yujialiang Coal Mine 4-2 and 5-2 coal, Haragou Coal Mine 2-2, the roof stability of the 2-2 coal in the Bulianta Mine, the 1-2 coal in the Shangwan Mine, and the 1-2 coal in the Huojitujing coal mine have been classified. For space requirements, take Baode Coal Mine $8 \#$ coal 
TABLE 5: Excepting output and real output.

\begin{tabular}{ccccccccc}
\hline & Target output & \multicolumn{3}{c}{ Actual output } & \multicolumn{2}{c}{ Stable type } \\
\hline 0.00 & 0.00 & 0.00 & 1.00 & 0.0000 & 0.0020 & 0.0031 & 0.9965 & IV \\
0.00 & 0.00 & 1.00 & 0.00 & -0.0001 & -0.0013 & 1.0003 & -0.0025 & III \\
1.00 & 0.00 & 0.00 & 0.00 & 0.9941 & 0.0040 & 0.0008 & 0.0004 & I \\
0.00 & 0.00 & 1.00 & 0.00 & -0.0005 & 0.0058 & 0.9933 & -0.0020 & III \\
0.00 & 1.00 & 0.00 & 0.00 & 0.0011 & 1.0043 & -0.0029 & 0.0004 & II \\
0.00 & 0.00 & 0.00 & 1.00 & 0.0006 & 0.0006 & -0.0031 & 1.0017 & IV \\
1.00 & 0.00 & 0.00 & 0.00 & 1.0015 & -0.0034 & 0.0007 & 0.0003 & I \\
0.00 & 1.00 & 0.00 & 0.00 & 0.0034 & 1.0020 & -0.0028 & 0.0004 \\
\hline
\end{tabular}

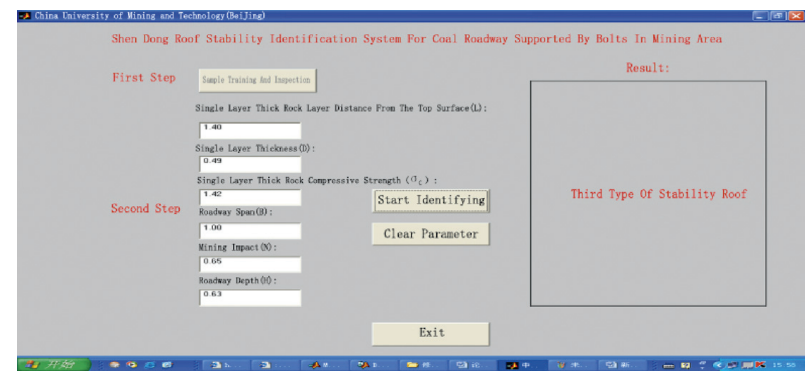

FIGURE 3: Identifying system classification of stability.

TABLE 6: The output of network and its equal line.

\begin{tabular}{|c|c|c|}
\hline Neural network output & Type of roof stability & Contour \\
\hline 1.000 .000 .000 .00 & I (stable type) & $10 \sim 8$ \\
\hline 0.001 .000 .000 .00 & II (medium stable type) & $8 \sim 6$ \\
\hline $\begin{array}{llll}0.00 & 0.00 & 1.00 & 0.00\end{array}$ & III (falling type) & $6 \sim 4$ \\
\hline $\begin{array}{llll}0.00 & 0.00 & 0.00 & 1.00\end{array}$ & IV (easy to fall type) & $4 \sim 2$ \\
\hline
\end{tabular}

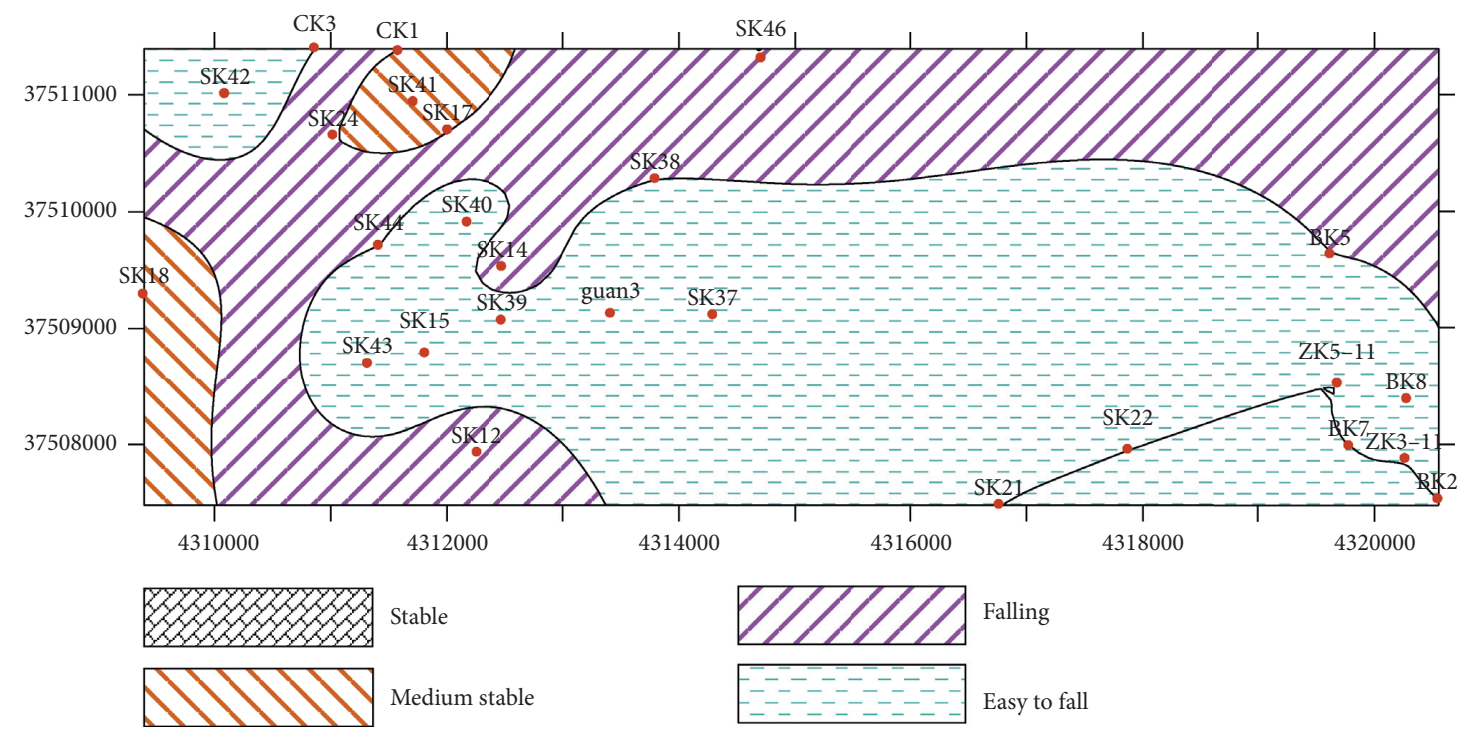

FIGURE 4: The stability equal line fig of number 8 coal seam roadway roof of Baode.

roadway roof and Bulianta Coal 2-2 coal roadway roof stability classification as examples. According to the recognition result, the surfer software is used to draw the contour map of the stability of the roof of each coal mining roadway. When drawing the contour map of the stability of the roof, the four different results output by the network give the corresponding values. See Table 6, for specific assignments. 


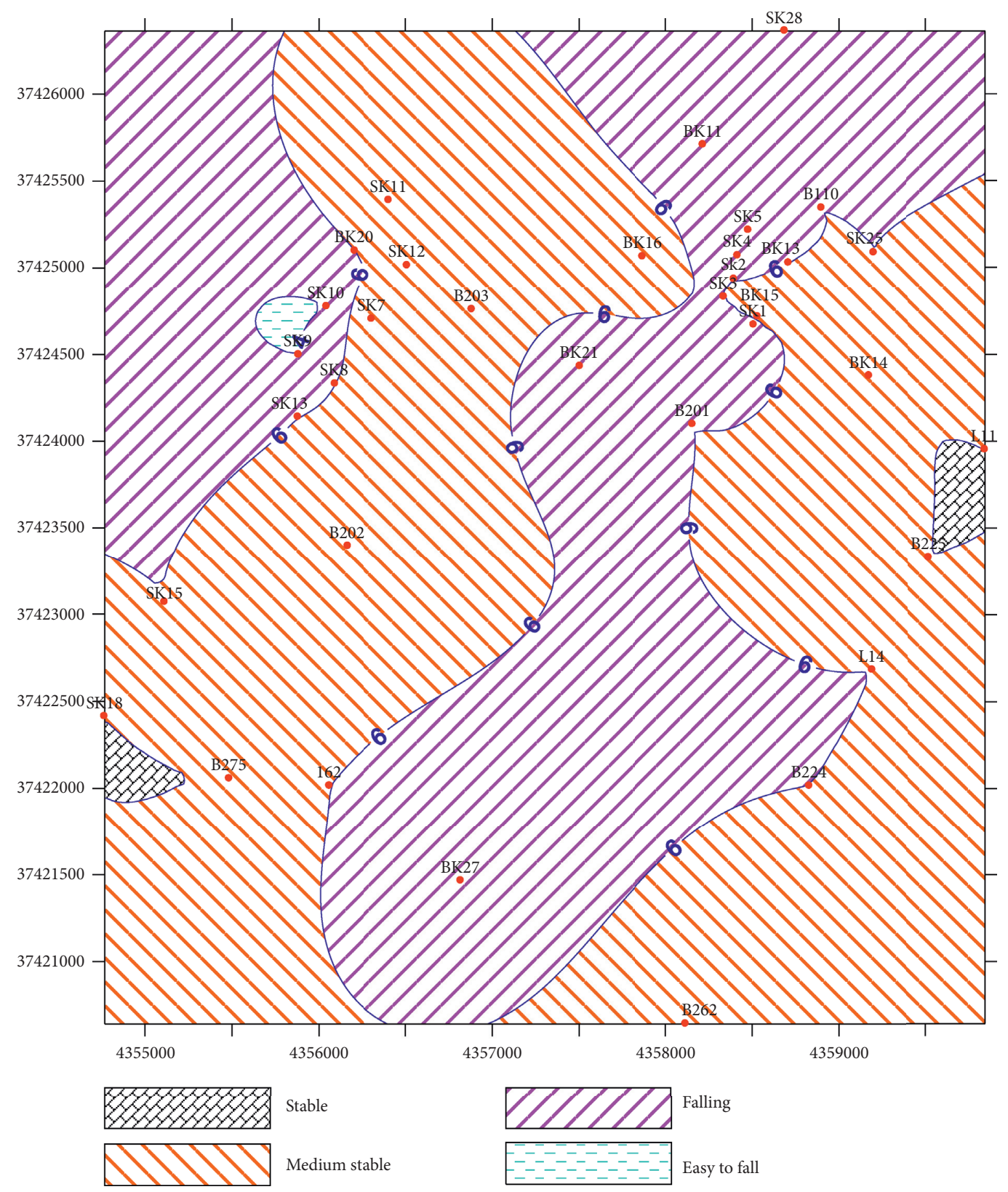

Figure 5: The stability equal line figure of number 2-2 coal seam roadway roof of Bulianta.

The six data obtained by the analysis constitute the input parameters of the software recognition system and the corresponding output results can be obtained. All output results of different mining coal seams in different mines are assigned according to Table 6. Classification results and corresponding assignments of each coal seam in each mine. These assigned values and their corresponding borehole coordinates are input into the surfer software to draw contour maps of roof stability of different mines, different coal seams, and different regions.
5.1. Classification Results of Roof Stability of Coal Roadways Mining in Shendong District of Mine

5.1.1. Baode Mine 8\# Coal Seam Roof Stability Classification Results. For the stability classification of coal roadway roof of Baode Coal Mine, it is mainly based on the 26 drilling data provided by Baode Coal Mine. The classification involves four panels of the $8 \#$ coal seam currently being mined by Baode Coal Mine, namely, one panel, two panels, three panels, and five panels. The data obtained from the analysis 
of the borehole data provided is combined with the actual engineering conditions of the roadway in the classification area of Baode Coal Mine, and the neural network input layer data is input to the neural network model for recognition. According to the aforementioned method, the recognition result is given to the value required for drawing the contour map, and the top plate stability contour map shown in Figure 4 is drawn. It can be seen from the figure that the overall stability of the roof of coal roadway in No. 8 mining coal mine in Baode Mine is poor. Except for the three-panel part of the four panels, the top panel is a medium stable roof panel, and the rest of the regions are falling or prone to falling roof panels. This classification result is in good agreement with the actual situation on site.

\subsection{Classification Results of Roof Stability of 2-2 Coal Seam in} Bulianta Mine. The stability of the roof of the 2-2 coal seam roadway in Bulianta Mine is mainly derived from the 39 borehole data provided by the mine area and combined with the actual engineering conditions of the roadway where the borehole is located. The area involved in the roof classification is the mining roadway and part of the unmined part in the five working faces of the 32201 32205 three-panel area of the Bulian Tower Mine (this part of the roadway span is processed according to the actual situation of the roadway in the mining and mining area), as shown in Figure 5. Judging from the classification results, the overall stability of the roof in the classified areas of the Bulianta Mine is general. Most of the roofs are medium stable and falling roofs, and only a few areas are stable and easy to fall roofs. This classification result is in good agreement with the actual situation of the roadway roof in the mine production.

\section{Conclusion}

(1) Based on the in-depth analysis of the factors influencing the stability of coal roadway roof in Shendong mining area, the classification index of coal roadway roof stability in Shendong mining area is proposed. It is proposed that the strength, thickness, span, distance from the roof surface, roof-to-height ratio, and roadway depth of the single-layer thick rock layer closest to the roadway roof surface are classified indicators for the stability of the bolt coal roadway roof in the Shendong mining area.

(2) In view of the problem of large calculation amount, large number of iterations, and slow convergence speed of the $\mathrm{BP}$ algorithm, it is improved by adding a momentum term to the BP algorithm and finetuning the correction amount of the weight value so that the learning avoids falling into the local minimum and plays a stabilizing role.

(3) A BP neural network prediction model for roof stability of coal roadway supported by bolts in Shendong mining area has been established. After verification, the established BP neural network prediction model has high error accuracy and good recognition effect. In order to facilitate the application of the model in the field, in the existing model based on Matlab6.5 programming, the stability classification software identification system for the roof of coal roadway supported by bolts in Shendong mining area was developed.

(4) According to the recognition results, the surfer software is used to draw the contour maps of the stability of the coal roadway roofs in each mine, and the classification results contour maps are compared with the actual maintenance status of the coal roadway roofs in the mine production surveyed on site. The results show that the classification results are more in line with the actual situation on site.

\section{Data Availability}

The data used to support the findings of this study are included in the article, which are based on the geological data of the site.

\section{Conflicts of Interest}

The authors declare that they have no conflicts of interest.

\section{Acknowledgments}

This study was supported by the National Natural Science Foundation of China (51804114 and 51774130), Hunan Graduate Education Innovation Project and Professional Ability Improvement Project (CX20200985), and Open Fund Project of Hunan Province Key Laboratory of Clean Utilization of Coal Resources and Mine Environmental Protection (E22014). The financial supports were greatly appreciated.

\section{References}

[1] M. C. He, H. H. Yuan, H. W. Jing, F. R. Wang, and H. H. Jing, Theory and Practice of Bolt Support in China's Coal Mines, pp. 149-169, Science Press, Beijing, China, 2004.

[2] H. P. Kang, "Sixty years development and prospects of rock bolting technology for under-ground coal mine roadways in China," Journal of China University of Mining \& Technology, vol. 45, no. 6, pp. 1071-1081, 2016.

[3] W. Yu and F. Liu, "Stability of close chambers surrounding rock in deep and comprehensive control technology," Advances in Civil Engineering, vol. 2018, pp. 1-18, 2018.

[4] W. Yu, B. Pan, F. Zhang, S. Yao, and F. Liu, "Deformation characteristics and determination of optimum supporting time of alteration rock mass in deep mine," KSCE Journal of Civil Engineering, vol. 23, no. 11, pp. 4921-4932, 2019.

[5] W. Yu, G. Wu, B. An, and P. Wang, "Experimental study on the brittle-ductile response of a heterogeneous soft coal rock mass under multifactor coupling," Geofluids, vol. 2019, Article ID 5316149, 15 pages, 2019.

[6] J. L. Xie, J. L. Xu, and W. B. Zhu, "Gray algebraic curve modelbased roof separation prediction method for the warning of roof fall accidents," Arabian Journal of Geosciences, vol. 9, no. 8, 2016.

[7] L. Y. Zhu, W. S. Lv, P. Yang, Z. K. Wang, and K. Wang, "Statistical analysis and occurrence laws of coal mine accidents of China from 2007 to 2016," Safety in Coal Mines, vol. 49, no. 7, pp. 237-240, 2018.

[8] N. Zhang, C. L. Han, and Z. Z. Xie, "Theory of continuous beam control and high efficiency supporting technology in 
coal roadway," Journal of Mining And Strata Control Engineering, vol. 1, no. 2, pp. 48-55, 2019.

[9] Y. J. Zhu and T. Feng, "Research on dynamic stability classification of bolt support for super-long coal roadway roof," Journal of China Coal Society, vol. 37, no. 4, pp. 565-570, 2012.

[10] W. Li, Y. Ye, Q. Wang, X. Wang, and N. Hu, "Fuzzy risk prediction of roof fall and rib spalling: based on FFTA-DFCE and risk matrix methods," Environmental Science and Pollution Research, vol. 27, no. 8, pp. 8535-8547, 2020.

[11] M. Zhang and Y. Zhang, "Stability evaluation method for gateways in closely spaced coal seams and surrounding rock control technology," Arabian Journal for Science and Engineering, vol. 43, no. 10, pp. 5469-5485, 2018.

[12] D. Y. Li, H. M. Li, and Y. Zhou, "Study on the evaluation method of scientized mining by extension theory," Journal of Mining \& Safety Engineering, vol. 30, no. 1, pp. 57-62, 2013.

[13] S. Mahdevari, K. Shahriar, M. Sharifzadeh, and D. D. Tannant, "Stability prediction of gate roadways in long wall mining using artificial neural networks," Neural Computing and Applications, vol. 28, no. 11, pp. 3537-3555, 2017.

[14] M. Farid, M. M. HosseinAbadi, A. Yazdani-Chamzini, S. H. Yakhchali, and M. H. Basiri, "Developing a new model based on neuro-fuzzy system for predicting roof fall in coal mines," Neural Computing and Applications, vol. 23, no. 1, pp. 129-137, 2013.

[15] Y. He, Y. Zhang, and L. Xiang, "Study of application model on BP neural network optimized by fuzzy clustering," in Proceedings of the 4th Mexican International Conference on Artificial Intelligence, pp. 712-720, Springer, Monterrey, Mexico, November 2005.

[16] Y. Shao, Q. Chen, and D. Zhang, "The application of improved BP neural network algorithm in lithology recognition," in Proceedings of the Third International Symposium on Intelligence Computation and Applications, pp. 342-349, Springer, Wuhan, China, December 2008.

[17] W. Jia, D. Zhao, T. Shen, S. Ding, Y. Zhao, and C. Hu, “An optimized classification algorithm by BP neural network based on PLS and HCA," Applied Intelligence, vol. 43, no. 1, pp. 176-191, 2015.

[18] H. Liu, N. Ma, F. Zhao, and F. Liu, "New bolting structure of fractured roof based on the Bossinesq equations," Mining Science and Technology (China), vol. 20, no. 2, pp. 260-265, 2010. 